\title{
Protective effect of crocin on ultraviolet B-induced dermal fibroblast photoaging
}

\author{
MINGWU DENG ${ }^{1 *}$, DONG LI $^{1 *}$, YICHEN ZHANG $^{2}$, GUANGDONG ZHOU $^{1}$, \\ WEI LIU ${ }^{1}$, YILIN CAO ${ }^{1}$ and WENJIE ZHANG ${ }^{1}$ \\ ${ }^{1}$ Department of Plastic and Reconstructive Surgery, Shanghai 9th People's Hospital, Shanghai Jiao Tong University \\ School of Medicine, Shanghai Key Laboratory of Tissue Engineering, National Tissue Engineering Center of China, \\ Shanghai 200011; ${ }^{2}$ Shanghai Starriver Bilingual School, Shanghai 201108, P.R. China
}

Received December 7, 2017; Accepted May 11, 2018

DOI: $10.3892 / \mathrm{mmr} .2018 .9150$

\begin{abstract}
Ultraviolet B (UVB) radiation induces the production of reactive oxygen species (ROS), resulting in the aging of dermal fibroblasts. Crocin, a bioactive constituent of Crocus sativus, possesses anti-oxidation effects. The purpose of the present study was to evaluate the protective effect of crocin on UVB-induced dermal fibroblast photoaging. Human dermal fibroblasts were isolated and cultured with different concentrations of crocin prior to and following exposure to UVB irradiation. The senescent phenotypes of cells were evaluated, including cell proliferation, cell cycle, senescence-associated $\beta$-galactosidase (SA- $\beta$-gal) expression, intracellular ROS, expression of antioxidant protein glutathione peroxidase 1 (GPX-1) and extracellular matrix protein collagen type 1 (Col-1). Crocin rescued the cell proliferation inhibited by UVB irradiation, prevented cell cycle arrest and markedly decreased the number of SA- $\beta$-gal-positive cells. In addition, crocin reduced UVB-induced ROS by increasing GPX-1 expression and other direct neutralization effects. Furthermore, crocin promoted the expression of the extracellular matrix protein Col-1. Crocin could effectively prevent UVB-induced cell damage via the reduction of intracellular ROS; thus, it could potentially be used in the prevention of skin photoaging.
\end{abstract}

Correspondence to: Professor Yilin Cao or Professor Wenjie Zhang, Department of Plastic and Reconstructive Surgery, Shanghai 9th People's Hospital, Shanghai Jiao Tong University School of Medicine, Shanghai Key Laboratory of Tissue Engineering, National Tissue Engineering Center of China, 639 Zhizaoju Road, Shanghai 200011, P.R. China

E-mail: yilincao@yahoo.com

E-mail: wenjieboshi@aliyun.com

${ }^{*}$ Contributed equally

Key words: crocin, photoaging, reactive oxygen species, antioxidant, glutathione peroxidase 1

\section{Introduction}

Skin photoaging is a cosmetic concern worldwide, and is characterized by atrophy of the skin, coarse wrinkles and leathery skin (1). Sun exposure is the main factor leading to photoaging, primarily due to ultraviolet (UV) radiation. There are three categories of ultraviolet light according to its wavelength, including UVA (320-400 nm), UVB (290-320 nm) and UVC (200-290 nm) (2). UVB is considered to be the most important factor associated with skin photoaging (3). UVB radiation exposure can induce the production of reactive oxygen species (ROS) in dermal fibroblasts, including the hydroxyl free radical, superoxide anion, singlet oxygen and hydrogen peroxide (4). Increased ROS levels can damage dermal fibroblasts, the most important cell type in the dermis that produces extracellular matrix (ECM). Subsequently, the synthesis of ECM could be inhibited and degradation may be accelerated, resulting in skin aging (2). Antioxidants, including vitamins C and E, and coenzyme Q10, could inhibit and neutralize ROS; thus, they have been suggested for the treatment and prevention of skin photoaging (5).

Saffron has been used in traditional Chinese medicine for a number of years. It has been traditionally used for the treatment of many types of disease, including neurodegenerative disorders, coronary artery diseases, respiratory diseases and gastrointestinal diseases (6). The therapeutic effects of saffron are associated with some of its components. Crocin is one of the main and active constituents isolated from saffron. It has been shown previously that crocin exhibits multiple activities, including anti-cancer, anti-inflammatory and anti-oxidation effects in various cell types (7). Lv et al (8) reported that crocin exerts an anti-oxidative effect against $\mathrm{H}_{2} \mathrm{O}_{2}$-induced apoptosis in retinal ganglion cells.

Based on the anti-oxidant capacity of crocin, it was speculated that it may prevent UVB-induced skin aging. In the present study, the protective effects of crocin against UVB-induced damage were investigated in cultured human dermal fibroblasts.

\section{Materials and methods}

Preparation of crocin. Crocin (Sigma-Aldrich; Merck KGaA, Darmstadt, Germany) was dissolved in sterile PBS solution at 
a concentration of $10 \mathrm{mM}$, stored at $-20^{\circ} \mathrm{C}$ and then freshly thawed at room temperature prior to each use.

Antioxidant effects of crocin. To test the antioxidant effects of crocin, 1,1-diphenyl-2-picrylhydrazyl (DPPH; Sigma-Aldrich; Merck KGaA) radical scavenging activity was measured as previously described (9). Reaction mixtures (200 $\mu \mathrm{l})$ containing DPPH and a serial dilution of crocin $(100-800 \mu \mathrm{M})$ were placed in a 96-well plate at room temperature in the dark for $30 \mathrm{~min}$, then the absorbance was measured at $515 \mathrm{~nm}$ using a Varioskan Flash Spectral Scanning Multimode Reader (Thermo Fisher Scientific, Inc., Waltham, MA, USA). The inhibition rate was determined using the following equation: Inhibition rate $(\%)=\left[1-\left(\mathrm{A}_{\text {sample }} / \mathrm{A}_{\text {control }}\right)\right] \times 100$. Where $\mathrm{A}$ refers to the absorbance measured at $515 \mathrm{~nm}$.

Cell isolation and culture. Dermal fibroblasts were isolated from human foreskin specimens. Samples were obtained from five donors (age, 6-12 years) who underwent a routine circumcision procedure at Shanghai 9th People's Hospital between January 2016 and January 2017. Written informed consent was obtained. The present study was approved by The Ethics Committee of Shanghai 9th People's Hospital, Shanghai Jiao Tong University School of Medicine (Shanghai, China). A single-cell suspension was obtained as previously described (10). Cells were then suspended in Dulbecco's modified Eagle's medium (Invitrogen; Thermo Fisher Scientific, Inc.) supplemented with $10 \%$ fetal bovine serum (HyClone; GE Healthcare Life Sciences, Logan, UT, USA), $300 \mu \mathrm{g} / \mathrm{ml}$ L-glutamine, $100 \mathrm{U} / \mathrm{ml}$ penicillin and $100 \mu \mathrm{g} / \mathrm{ml}$ streptomycin (all Sigma-Aldrich; Merck KGaA). Cells were maintained at $37^{\circ} \mathrm{C}$ in a humidified atmosphere containing $5 \% \mathrm{CO}_{2}$ and passaged by trypsinization with $0.25 \%$ trypsin-EDTA (Gibco; Thermo Fisher Scientific, Inc.) every 3-5 days. Cells at passage 3-5 were used in the following experiments.

Crocin toxicity analysis. Fibroblasts were seeded in a 96-well plate at a density of 2,000 cells/well and treated with different concentrations of crocin $(0,12.5,50$ and $100 \mu \mathrm{M})$ and subsequently maintained at $37^{\circ} \mathrm{C}$ in a humidified atmosphere containing $5 \% \mathrm{CO}_{2}$ for $72 \mathrm{~h}$. Cell proliferation was then measured using a Cell Counting Kit-8 (CCK-8; Beyotime Institute of Biotechnology, Haimen, China), according to the manufacturer's instructions. Untreated cells served as the control.

$U V B$ irradiation. Fibroblasts were cultured in 96-well $(2,000$ cells/well $)$ or 6 -well plates $\left(1 \times 10^{5}\right.$ cells/well $)$ in the aforementioned supplemented DMEM mixture, and maintained at $37^{\circ} \mathrm{C}$ for $24 \mathrm{~h}$. Following a further $24 \mathrm{~h}$ of incubation at $37^{\circ} \mathrm{C}$ with or without crocin $(0,12.5,50$ and $100 \mu \mathrm{M})$, culture medium was replaced with PBS. Cells were then exposed to UVB light (Philips $311 \mathrm{~nm}$, TL 20W/01; Philips Lighting Holding B.V., Eindhoven, The Netherlands) at a total dose of $100 \mathrm{~mJ} / \mathrm{cm}^{2}$. Following irradiation, the medium was replaced with culture medium with or without crocin, and cells were maintained at $37^{\circ} \mathrm{C}$ in a humidified atmosphere containing $5 \% \mathrm{CO}_{2}$ for 24 or $72 \mathrm{~h}$ for further analyses. Cells treated with UVB irradiation and $150 \mu \mathrm{M}$ vitamin $\mathrm{C}$ (Vit C;
Sigma-Aldrich; Merck KGaA) served as a positive control. The following experiments were then performed.

Determination of cell proliferation. Cell proliferation was measured at $72 \mathrm{~h}$ post-irradiation using a CCK-8 kit (Beyotime Institute of Biotechnology), according to the manufacturer's instructions. Results are expressed as the relative cell proliferation (\%) with respect to the control cells (cells without UVB irradiation or crocin treatment).

Cell cycle analysis. At $24 \mathrm{~h}$ post-UVB radiation, $5 \times 10^{5}$ cells were harvested by $0.25 \%$ Trypsin-EDTA and then fixed in $70 \%$ ethanol overnight at $4^{\circ} \mathrm{C}$. Fixed cells were washed twice with PBS and then incubated with $1.5 \mathrm{mg} / 1$ RNase A (Sigma-Aldrich; Merck KGaA) for $1 \mathrm{~h}$ at $37^{\circ} \mathrm{C}$, followed by staining with $5 \mu \mathrm{l}$ of propidium iodide (Sigma-Aldrich; Merck $\mathrm{KGaA}$ ) for $20 \mathrm{~min}$ on ice. DNA content was assessed using an Epics Altra Flow Cytometer (Beckman Coulter, Inc., Brea, CA, USA), and analyzed with Modi Fit LT v2.0 software (Verity Software House, Inc., Topsham, ME, USA).

$\beta$-galactosidase (SA- $\beta$-gal) staining. To measure the cell-aging rate, SA- $\beta$-gal staining was performed at $72 \mathrm{~h}$ post-irradiation using a Senescence $\beta$-Galactosidase staining kit purchased from Cell Signaling Technology, Inc. (Danvers, MA, USA; cat. no. 9860). Cells were washed in PBS, fixed for $10 \mathrm{~min}$ at room temperature in $4 \%$ paraformaldehyde and stained according to manufacturer's instructions. Five random fields from each sample ( $\mathrm{n}=3$ samples/group) were selected to observe under a light microscope (Nikon Eclipse 90i; Nikon Corporation, Tokyo, Japan), and the number of SA- $\beta$-gal-positive cells was counted using Image-Pro Plus 6.0 software (Media Cybernetics, Inc., Rockville, MD, USA). The aging rate was determined as the percentage of positive cells out of the total number of cells.

Measurement of intracellular ROS. Intracellular ROS levels were determined by 2',7'-dichlorodihydrofluoresce in diacetate ( $\mathrm{DCFH}_{2}-\mathrm{DA}$; Sigma-Aldrich; Merck KGaA) staining. Briefly, immediately following UVB irradiation, cells were incubated with $\mathrm{DCFH}_{2}$-DA $(10 \mathrm{mM})$ at $37^{\circ} \mathrm{C}$ for $20 \mathrm{~min}$. Following this, half of the cells were observed under a fluorescent microscope (Olympus IX70-S1F2; Olympus Corporation, Tokyo, Japan), and the other half of the cells were collected and analyzed with an Epics Altra Flow Cytometer, as described previously (11).

Reverse transcription-quantitative polymerase chain reaction $(R T-q P C R)$ analysis. Cells $\left(2 \times 10^{6}\right)$ were collected at $72 \mathrm{~h}$ post-irradiation. Total RNA was extracted using TRIzol ${ }^{\circledR}$ reagent (Invitrogen; Thermo Fisher Scientific, Inc.), and cDNA was synthesized from $2 \mu \mathrm{g}$ total RNA using $200 \mathrm{U}$ of reverse transcriptase (MMLV-RT) and 20 pM oligo dT (Promega Corporation, Madison, WI, USA) at $42^{\circ} \mathrm{C}$ for $1 \mathrm{~h}$. The expression of pro-collagen I was determined by qPCR using SYBR Green PCR Master mix (Applied Biosystems, Thermo Fisher Scientific, Inc.). The thermocycling conditions were as follows: Initial denaturation at $95^{\circ} \mathrm{C}$ for $10 \mathrm{~min}$, followed by 40 cycles at $95^{\circ} \mathrm{C}$ for $30 \mathrm{sec}, 60^{\circ} \mathrm{C}$ for $30 \mathrm{sec}$ and $72^{\circ} \mathrm{C}$ for $45 \mathrm{sec}$, using the Strata Gene Mx3000p (Agilent Technologies, Inc., Santa Clara, CA, USA). Expression was quantified using the 
$2^{-\Delta \Delta \mathrm{Cq}}$ method (12). The primers employed were as follows: Pro-collagen I, forward: 5'-CTCGAGGTGGACACCACC CT-3' and reverse: 5'-CAGCTGGATGGCCACATCGG-3'. All amplifications were run in triplicate and the results were normalized to the housekeeping gene GAPDH, the primers of which were as follows: Forward: 5'-CAAAAGGGTCATCAT CTCTG-3' and reverse: 5'-CCTGCTTCACCACCTTCTTG-3'. Three independent experiments were performed.

Western blot analysis. Cells $\left(2 \times 10^{6}\right)$ were collected at $72 \mathrm{~h}$ post-irradiation. Total protein was extracted for western blot analysis and the expression of collagen type 1 (Col-1) and glutathione peroxidase 1 (GPX-1) was measured. Proteins were harvested and collected with radioimmunoprecipitation assay lysis buffer (Beyotime Institute of Biotechnology). Protein concentrations were determined with a bicinchoninic acid protein assay. Subsequently, proteins (20 $\mu \mathrm{g} /$ lane) were separated by $12 \%$ SDS-PAGE. Following electrophoresis at $100 \mathrm{~V}$ for $2 \mathrm{~h}$, proteins were transferred to polyvinylidene difluoride membranes at $350 \mathrm{~mA}$ for $90 \mathrm{~min}$. The membranes were blocked with $5 \%$ non-fat milk in Tris-buffered saline and Tween 20 (TBST) at room temperature for $2 \mathrm{~h}$, followed by incubation with the following primary antibodies overnight at $4^{\circ} \mathrm{C}$ : Anti-Col-1 (cat. no. ab6308; 1:1,000; Abcam, Cambridge, UK), anti-GPX-1 (cat. no. ab108427; 1:2,000; Abcam) and $\beta$-actin (cat. no. 4970S; 1:2,000; Cell Signaling Technology, Inc.). The membranes were washed three times with TBST and subsequently incubated with horseradish peroxidase-conjugated goat anti-mouse secondary antibody (cat. no. 115-035-062; 1:2,000; Jackson ImmunoResearch Laboratories, Inc., West Grove, PA, USA) at room temperature for $2 \mathrm{~h}$. Protein expression levels were analyzed by visualizing the bands with enhanced chemiluminescence (Pierce, Rockford, USA). ImageJ 1.50i software (National Institutes of Health USA) was used for densitometry.

Statistical analysis. Data are expressed as the mean \pm standard deviation. Unpaired t-tests were used for direct comparisons between the UVB and the UVB + crocin groups. For multiple comparisons, one-way analysis of variance followed by Tukey's post hoc test was performed. All analyses were performed using SPSS v.13.0 software (SPSS, Inc., Chicago, IL, USA). $\mathrm{P}<0.05$ was considered to indicate a statistically significant difference.

\section{Results}

Cytotoxicity of crocin. To test the potential cytotoxicity of crocin on dermal fibroblasts, cells were treated with various concentrations $(0,12.5,50$ and $100 \mu \mathrm{M})$ of crocin for $72 \mathrm{~h}$ prior to measuring the levels of proliferation using a CCK-8 assay. As shown in Fig. 1, crocin did not inhibit the proliferation of cells at the concentrations tested, up to $100 \mu \mathrm{M}$, indicating that crocin at this dose range may not be toxic to fibroblasts.

Crocin rescues the cell proliferation inhibited by $U V B$ irradiation. To determine the optimal dose of UVB irradiation, fibroblasts were exposed to a range of UVB doses $(0,25$, 50 and $100 \mathrm{~mJ} / \mathrm{cm}^{2}$ ) and a CCK-8 kit was used to measure cell proliferation following $72 \mathrm{~h}$. UVB irradiation significantly

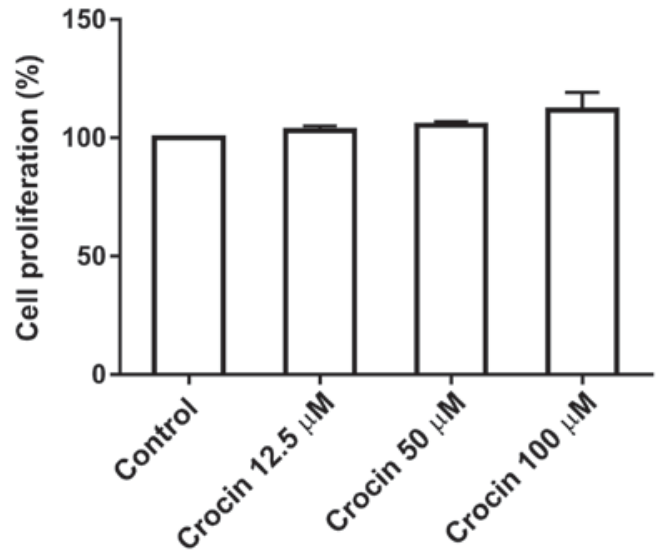

Figure 1. Effects of crocin $(0,12.5,50$ and $100 \mu \mathrm{m})$ on the proliferation of dermal fibroblasts.

inhibited cell proliferation at the dose of $100 \mathrm{~mJ} / \mathrm{cm}^{2}$ (Fig. 2A). Therefore, $100 \mathrm{~mJ} / \mathrm{cm}^{2}$ was selected for the subsequent experiments. Following pre-incubation with crocin $(12.5,50$ and $100 \mu \mathrm{M}$ ) for $24 \mathrm{~h}$, cells were irradiated by UVB and cell proliferation was measured following $72 \mathrm{~h}$. High doses (50 and $100 \mu \mathrm{M}$ ) of crocin significantly rescued the cell proliferation inhibited by UVB irradiation $(\mathrm{P}<0.05)$, and the rate was similar to that following Vit $\mathrm{C}$ treatment (Fig. 2B and C).

Crocin rescues $U V B$-induced cell cycle arrest. Flow cytometry analyses of the cell cycle are shown in Fig. 3. Cell populations in the $G_{2} / M$ phases were significantly increased following UVB irradiation, indicating that cells were arrested at the $\mathrm{G}_{2} / \mathrm{M}$ phase. As a positive control, Vit $\mathrm{C}$ treatment rescued cell cycle arrest as expected. High doses (50 and $100 \mu \mathrm{M})$ of crocin restored cell cycle arrest to levels similar to those of the control group (without UVB irradiation), indicating that crocin could rescue UVB-induced cell cycle arrest.

Crocin prevents $U V B$-induced cell aging. To determine whether crocin could prevent cells from UVB-induced photoaging, SA- $\beta$-gal staining was performed following UVB irradiation (Fig. 4A). A significant increase in SA- $\beta$-gal-positive cells was observed following UVB irradiation (Fig. 4). A decrease in SA- $\beta$-gal-positive cells was observed in the Vit C-treated group as well as in the high dose (50 and $100 \mu \mathrm{M})$ crocin-treated groups (Fig. 4). Statistical analysis confirmed that the percentage of SA- $\beta$-gal-positive cells was increased in the UVB group, and decreased following Vit $\mathrm{C}$ or crocin treatment (Fig. 4B).

Crocin reduces $U V B$-induced intracellular ROS. An increase in ROS is one of the most important mechanisms in photoaging (4). In the present study, UVB irradiation significantly increased intracellular ROS when compared with the control group, while the ROS levels were reduced by Vit $\mathrm{C}$ and crocin treatment (Fig. 5A). These results were confirmed by flow cytometric analysis of the fluorescent intensity following $\mathrm{DCFH}_{2}$-DA staining (Fig. 5B). To verify the possible underlying mechanisms, free radical scavenging activity of crocin was measured. Crocin inhibited DPPH radial activity in a dose-dependent manner (Fig. 5C), indicating that it could 

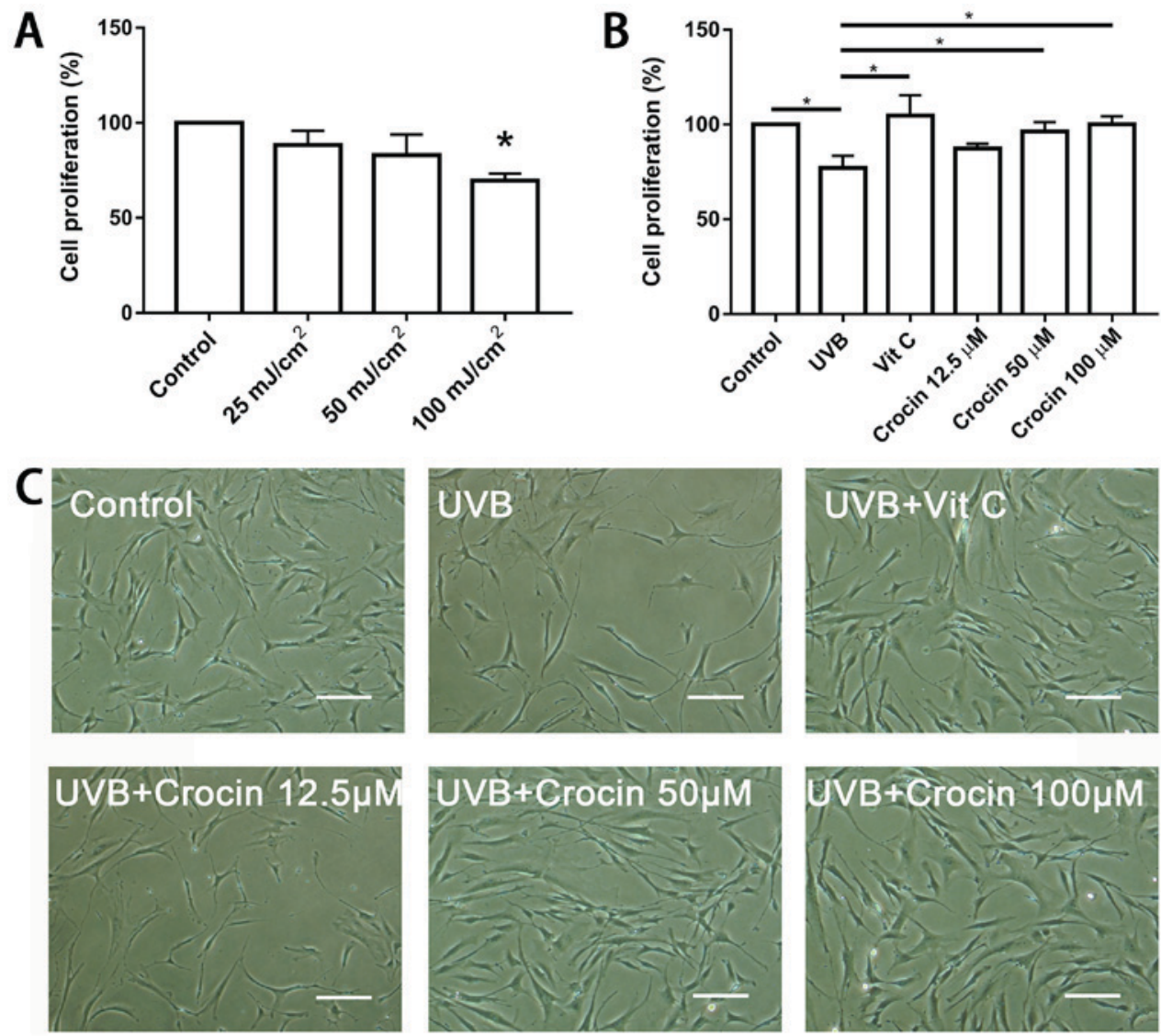

Figure 2. Crocin rescues the cell proliferation inhibited by UVB irradiation. (A) UVB irradiation inhibited fibroblast proliferation in a dose-dependent manner. " $\mathrm{P}<0.05$ vs. control. (B) Crocin rescued the cell proliferation inhibited by UVB irradiation. ${ }^{*} \mathrm{P}<0.05$, as indicated. (C) Morphology of fibroblasts at $72 \mathrm{~h}$ post-UVB irradiation. Scale bars, $150 \mu \mathrm{m}$. UVB, ultraviolet B; Vit C, vitamin C.

partially neutralize ROS. In addition, the expression of the antioxidant protein GPX-1 was measured by western blot analysis. An increase in GPX-1 expression was observed in the Vit $\mathrm{C}$ and crocin-treated groups (Fig. 5D and E), indicating that crocin may reduce UVB-induced ROS, partially via the enhanced expression of antioxidant protein GPX-1.

Crocin promotes the expression of ECM protein Col-1. Secretion of ECM is one of the major functions of dermal fibroblasts. A decrease in collagen secretion is commonly observed during skin aging (13). As shown in Fig. 6, a significant decrease in Col-1 expression was observed at the mRNA and protein level following UVB irradiation. In addition, Col-1 expression was upregulated by $\mathrm{Vit} \mathrm{C}$ and crocin treatment at the mRNA and protein levels, suggesting that cell functions were also restored following Vit $\mathrm{C}$ and crocin treatment.

\section{Discussion}

Extrinsic skin aging is caused by environmental factors including smoking, consuming alcohol, UV irradiation and common pollutants, which can lead to dermal fibroblast damage and aging $(14,15)$. UVB is considered to be one of the most important factors that contributes towards aging (16). In the present study, the results confirmed that UVB irradiation induced the production of intracellular ROS, arrested the cell cycle, inhibited cell proliferation and downregulated ECM production. Antioxidants, such as Vit $\mathrm{C}$, which scavenge ROS, are able to protect cells from UVB-induced damage (17).

Crocin, one of the main and active constituents of Crocus sativus, has been reported to have various bioactivities, including immunomodulatory, antitumor, anti-inflammation and antioxidant properties (18-22). Thus, it is not surprising that crocin could protect UVB-induced cell damage in cultured dermal fibroblasts, which was demonstrated by reduced intracellular ROS, rescued cell cycle and proliferation, and upregulated ECM production in the present study. One possible mechanism by which crocin may reduce intracellular ROS is by neutralizing ROS directly, as crocin could inhibit DPPH radical activity in a dose-dependent manner. Another potential mechanism could be that crocin upregulates antioxidant gene expression, which is supported by the upregulated expression of antioxidant protein GPX-1 following crocin treatment observed in the present study. However, an increased protective effect with $100 \mu \mathrm{M}$ crocin treatment was not observed when compared with $50 \mu \mathrm{M}$ crocin treatment. Intracellular ROS measurement revealed that ROS levels returned to basal (control) levels following 50 and $100 \mu \mathrm{M}$ crocin treatment, indicating that $50 \mu \mathrm{M}$ crocin may be sufficient to neutralize the UVB-induced ROS accumulation. Although GPX-1 expression was upregulated following crocin treatment, the regulatory pathway is still not clear. Therefore, it is worthy of further investigation in the future. 

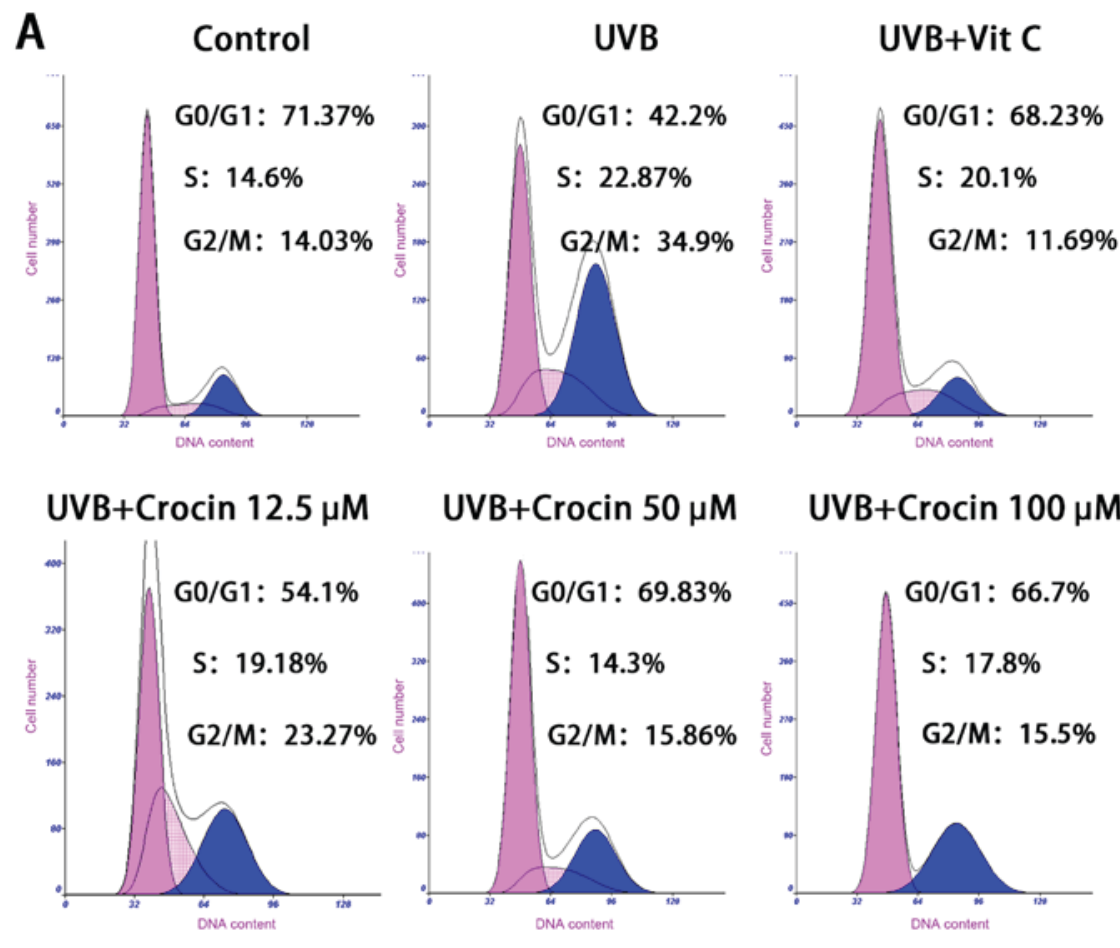

UVB+Crocin $50 \mu \mathrm{M}$

UVB+Crocin $100 \mu \mathrm{M}$

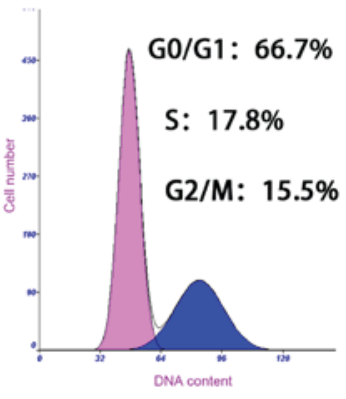

\begin{tabular}{cccc}
\hline B & G0/G1 & S & G2/M \\
\hline Control & $71.37 \pm 3.894$ & $14.6 \pm 3.483$ & $14.03 \pm 0.5033$ \\
UVB & $42.2 \pm 4.774^{\#}$ & $22.87 \pm 3.972$ & $34.9 \pm 4.66^{\#}$ \\
Vit C & $68.23 \pm 2.483^{*}$ & $20.1 \pm 3.82$ & $11.69 \pm 3.234^{*}$ \\
Crocin 12.5 $\mu \mathrm{M}$ & $54.1 \pm 3.208$ & $19.18 \pm 1.474$ & $23.27 \pm 3.723$ \\
Crocin 50 $\mu \mathrm{M}$ & $69.83 \pm 7.651^{*}$ & $14.3 \pm 1.808$ & $15.86 \pm 7.668^{*}$ \\
Crocin 100 $\mu \mathrm{M}$ & $66.7 \pm 5.151^{*}$ & $17.8 \pm 2.629$ & $15.5 \pm 6.899^{*}$ \\
\hline
\end{tabular}

Figure 3. Crocin rescues UVB-induced cell cycle arrest. (A) Representative histograms of the cell cycle analysis, as determined by flow cytometry. (B) Statistical analysis of cell cycle distribution from three independent experiments. ${ }^{*} \mathrm{P}<0.05$ vs. control; ${ }^{*} \mathrm{P}<0.05$ vs. UVB. UVB, ultraviolet $\mathrm{B}$; Vit $\mathrm{C}$, vitamin $\mathrm{C}$.
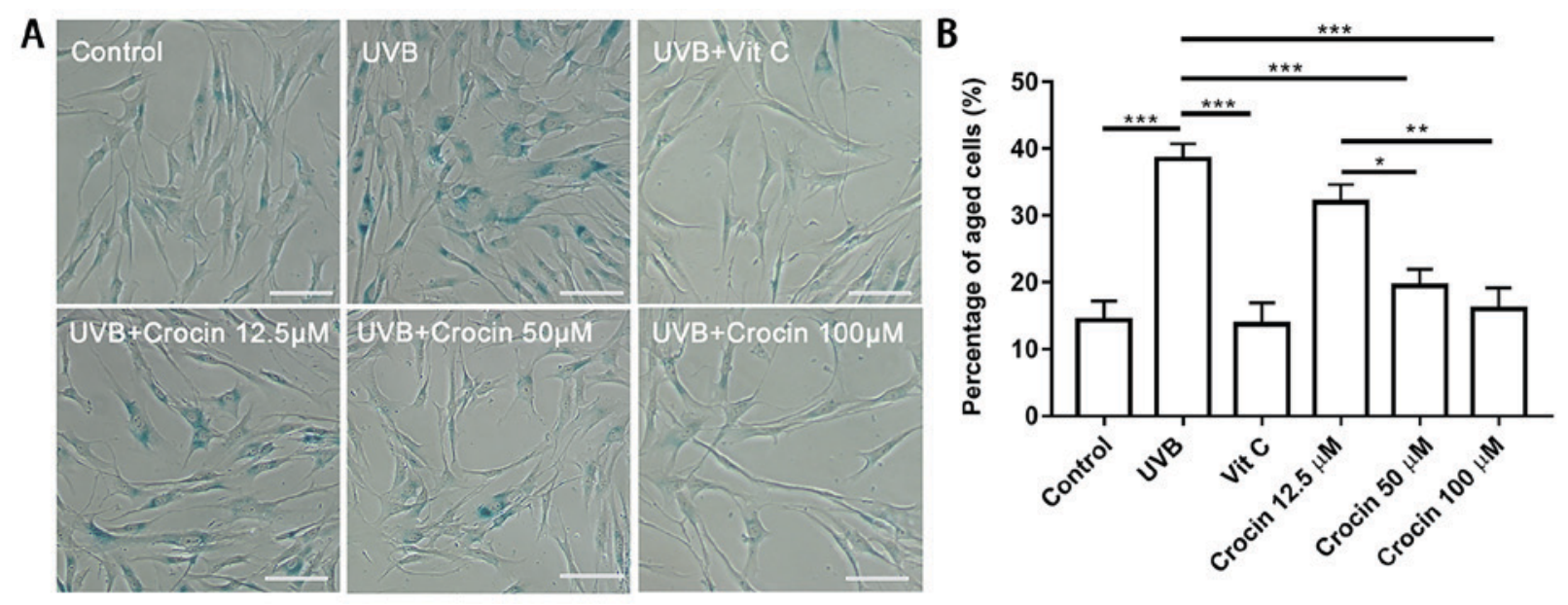

Figure 4. Crocin prevents UVB-induced cell aging. (A) Positive SA- $\beta$-gal staining indicated aging cells. Scale bars, $100 \mu$ m. (B) Percentage of SA- $\beta$-gal-positive cells was determined by counting 200 cells per dish. ${ }^{*} \mathrm{P}<0.05,{ }^{* * *} \mathrm{P}<0.01$ and ${ }^{* * * *} \mathrm{P}<0.001$, as indicated. UVB, ultraviolet B; Vit $\mathrm{C}$, vitamin $\mathrm{C}$; SA- $\beta$-gal, $\beta$-galactosidase. 

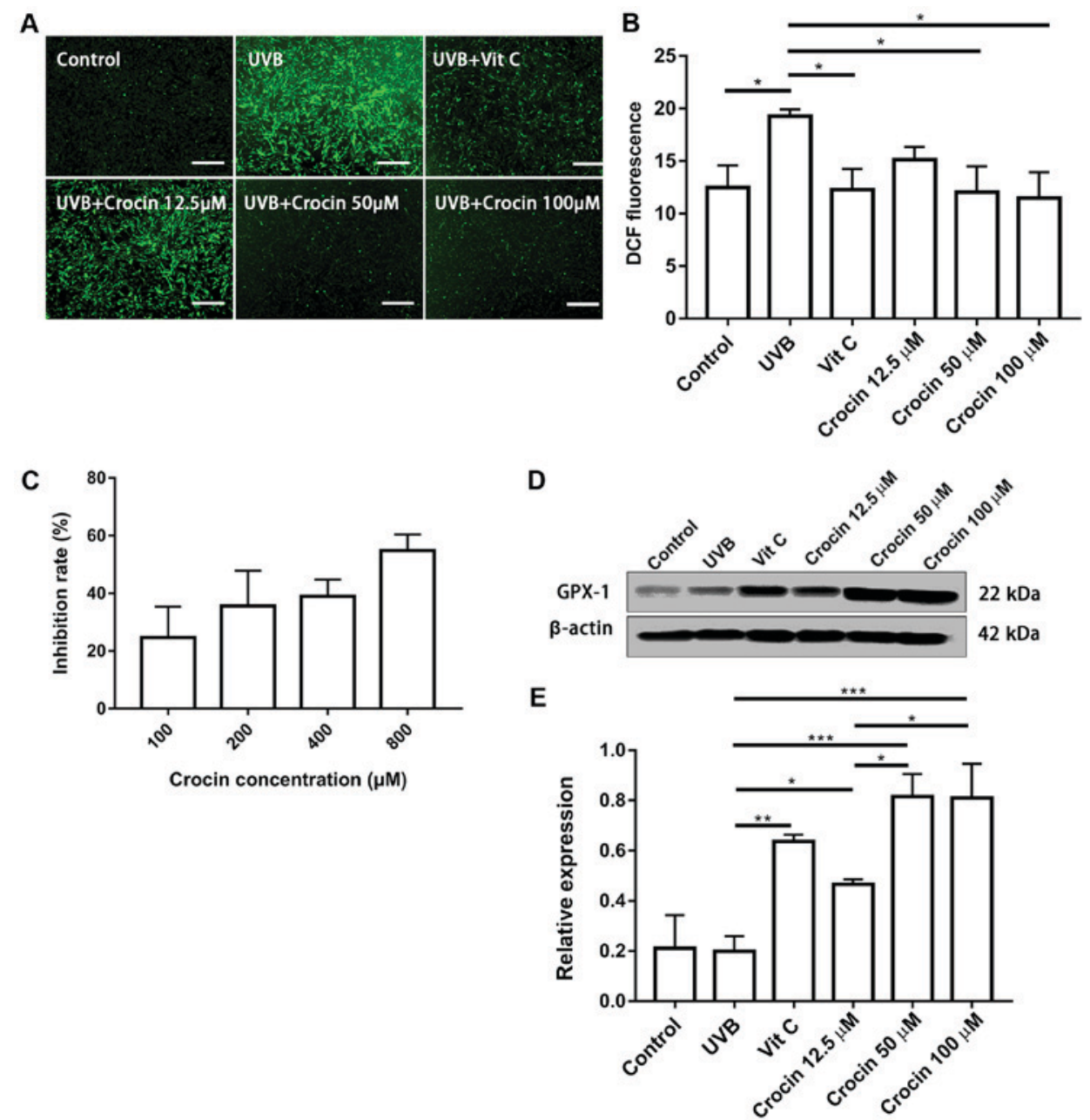

Figure 5. Crocin reduces UVB-induced intracellular ROS. (A) Intracellular ROS measured by DCFH -DA staining at 20 min post-UVB irradiation. Scale bars, $500 \mu \mathrm{m}$. (B) Intracellular ROS measured by DCFH2-DA staining and flow cytometry. (C) Antioxidant effect of crocin measured by 1,1-diphenyl-2-picrylhydrazyl radical-scavenging activity. (D) Western blot analysis of (E) GPX-1 expression at $72 \mathrm{~h}$ post-UVB irradiation. ${ }^{*} \mathrm{P}<0.05$, ${ }^{* *} \mathrm{P}<0.01$ and ${ }^{* * * *} \mathrm{P}<0.001$, as indicated. UVB, ultraviolet B; Vit C, vitamin C; ROS, reactive oxygen species; GPX-1, glutathione peroxidase 1; DCFH ${ }_{2}$-DA, 2',7'-dichlorodihydrofluoresce in diacetate.
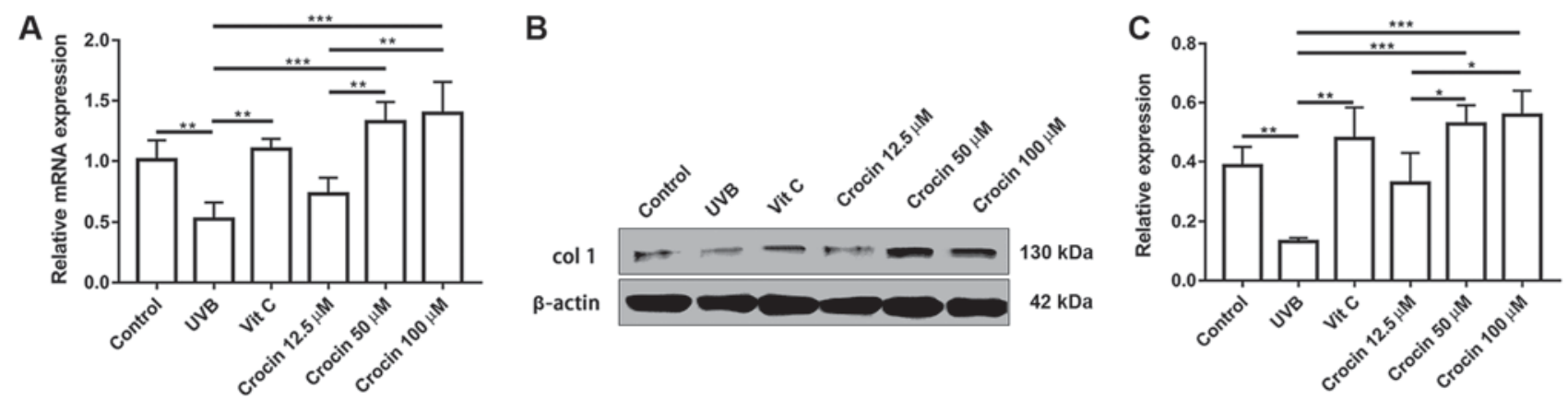

Figure 6. Crocin promotes the expression of collagen type 1. (A) Reverse transcription-quantitative polymerase chain reaction analysis of pro-collagen I at $72 \mathrm{~h}$ post-UVB irradiation. (B) Western blotting analysis of (C) collagen type 1 at $72 \mathrm{~h}$ post-UVB irradiation. ${ }^{*} \mathrm{P}<0.05,{ }^{* * *} \mathrm{P}<0.01$ and ${ }^{* * * *} \mathrm{P}<0.001$, as indicated. UVB, ultraviolet B; Vit C, vitamin C; col 1, collagen type 1.

As a natural product, crocin has been widely used as a spice and a food colorant. Previous studies have demonstrated that crocin does not cause damage to any major organ in experimental animals (23,24). Mohamadpour et al (25) evaluated the safety of crocin in healthy volunteers and confirmed that it is relatively safe. In the present study, the proliferation of dermal fibroblasts was not affected by crocin treatment at the tested concentrations; in fact, slight stimulation of cell growth was observed following crocin treatment. These results strongly suggest that crocin could be used in the clinic without significant toxicity at pharmacological doses. 
In the present study, the dose of UVB irradiation was optimized. Cells did not undergo apoptosis or necrosis at this exposure dose (data not shown), and the cell cycle was arrested at the $\mathrm{G}_{2} / \mathrm{M}$ phases. Cell senescence was observed by SA- $\beta$-gal staining, which produced similar results to those observed in previous studies (26-28). One limitation of the present study was that the protective effects of crocin against a higher dose of UVB-irradiation were not investigated. The anti-apoptotic potential of crocin has been demonstrated in previous studies $(29,30)$. Jia et al (11) reported that crocin protected retinal pigment epithelial cells from $\mathrm{H}_{2} \mathrm{O}_{2}$-induced damage through the upregulation of the anti-apoptotic genes B-cell lymphoma 2 (Bcl-2) and $\mathrm{Bcl}-2$-associated $\mathrm{X}$ protein. Thus, it is possible that crocin may exhibit protective effects at higher doses of irradiation via its anti-apoptotic activity. Another limitation of the present study was that cells were pre-treated with crocin $24 \mathrm{~h}$ prior to UVB irradiation. It remains to be investigated whether the application of crocin following irradiation would still protect the cells. Since crocin reduces intracellular ROS partially via the upregulation of antioxidant gene expression, it was speculated that the protective effects may be weaker than with pre-incubation due to the delayed expression of antioxidant genes. In future research, we aim to determine the anti-photoaging capacity of crocin in nude mice.

The protective effects of plant extracts on UVB-induced skin damage have been reported previously, including extracts from berries and herbs $(9,31)$. In general, the plant extracts contain a mixture of active components. In the present study, it was demonstrated that a single compound with a definite chemical structure possesses anti-photoaging activity. Furthermore, it is superior to the plant extracts that can be industrially synthesized with better quality control. The protective effects of crocin on photoaging fibroblasts suggest that it has potential applications in the protection against UVB-induced skin photoaging.

\section{Acknowledgements}

The authors deeply appreciated the contribution of members of the Shanghai Key Laboratory of Tissue Engineering, National Tissue Engineering Center of China (Shanghai, China) for providing valuable suggestions and discussions.

\section{Funding}

No funding was received.

\section{Availability of data and materials}

All data generated or analyzed during this study is included in this published article.

\section{Authors' contributions}

GZ, WL, YC and WZ conceived and designed the experiments. MD, DL and YZ performed the experiments. DL analyzed the data. MD, WZ and YC wrote and revised the manuscript.

\section{Ethics approval and consent to participate}

The present study was approved by The Ethics Committee of Shanghai 9th People's Hospital, Shanghai Jiao Tong University School of Medicine (Shanghai, China). Written informed consent was obtained from the donors.

\section{Patient consent for publication}

Not applicable.

\section{Competing interests}

The authors declare that they have no competing interests.

\section{References}

1. Gilchrest BA: Photoaging. J Invest Dermatol 133: E2-E6, 2013.

2. Kammeyer A and Luiten RM: Oxidation events and skin aging. Ageing Res Rev 21: 16-29, 2015.

3. Lee YR, Noh EM, Jeong EY, Yun SK, Jeong YJ, Kim JH, Kwon KB, Kim BS, Lee SH, Park CS and Kim JS: Cordycepin inhibits UVB-induced matrix metalloproteinase expression by suppressing the NF-kappaB pathway in human dermal fibroblasts. Exp Mol Med 41: 548-554, 2009.

4. Poon F, Kang S and Chien AL: Mechanisms and treatments of photoaging. Photodermatol Photoimmunol Photomed 31: 65-74, 2015.

5. Stern RS: Clinical practice. Treatment of photoaging. N Engl J Med 350: 1526-1534, 2004.

6. Boskabady MH and Farkhondeh T: Antiinflammatory, antioxidant, and immunomodulatory effects of Crocus sativus L. and its main constituents. Phytother Res 30: 1072-1094, 2016.

7. Samarghandian S, Azimi-Nezhad M, Borji A and Farkhondeh T: Effect of crocin on aged rat kidney through inhibition of oxidative stress and proinflammatory state. Phytother Res 30: 1345-1353, 2016.

8. Lv B, Chen T, Xu Z, Huo F, Wei Y and Yang X: Crocin protects retinal ganglion cells against $\mathrm{H} 2 \mathrm{O} 2$-induced damage through the mitochondrial pathway and activation of NF- $\kappa$ B. Int J Mol Med 37: 225-232, 2016

9. Chiang HM, Lin TJ, Chiu CY, Chang CW, Hsu KC, Fan PC and Wen KC: Coffea arabica extract and its constituents prevent photoaging by suppressing MMPs expression and MAP kinase pathway. Food Chem Toxicol 49: 309-318, 2011.

10. Chen FG, Zhang WJ, Bi D, Liu W, Wei X, Chen FF, Zhu L, Cui L and Cao Y: Clonal analysis of nestin(-) vimentin(+) multipotent fibroblasts isolated from human dermis. J Cell Sci 120: 2875-2883, 2007

11. Jia C, Lu Y, Bi B, Chen L, Yang Q, Yang P, Guo Y, Zhu J, Zhu N and Liu T: Platelet-rich plasma ameliorates senescence-like phenotypes in a cellular photoaging model. Rsc Adv 7: 3152-3160, 2017.

12. Livak KJ and Schmittgen TD: Analysis of relative gene expression data using real-time quantitative PCR and the 2(-Delta Delta C(T)) method. Methods 25: 402-408, 2001.

13. Brenneisen P, Sies H and Scharffetter-Kochanek K: Ultraviolet-B irradiation and matrix metalloproteinases: From induction via signaling to initial events. Ann N Y Acad Sci 973: 31-43, 2002.

14. Bernhard D, Moser C, Backovic A and Wick G: Cigarette smoke-an aging accelerator? Exp Gerontol 42: 160-165, 2007.

15. Wlaschek M, Tantcheva-Poor I, Naderi L, Ma W, Schneider LA, Razi-Wolf Z, Schüller J and Scharffetter-Kochanek K: Solar UV irradiation and dermal photoaging. J Photochem Photobiol B 63: 41-51, 2001.

16. Adil MD, Kaiser P, Satti NK, Zargar AM, Vishwakarma RA and Tasduq SA: Effect of Emblica officinalis (fruit) against UVB-induced photo-aging in human skin fibroblasts. J Ethnopharmacol 132: 109-114, 2010.

17. Farris PK: Topical vitamin C: A useful agent for treating photoaging and other dermatologic conditions. Dermatol Surg 31: 814-818, 2005. 
18. Deslauriers AM, Afkhami-Goli A, Paul AM, Bhat RK Acharjee S, Ellestad KK, Noorbakhsh F, Michalak M and Power C: Neuroinflammation and endoplasmic reticulum stress are coregulated by crocin to prevent demyelination and neurodegeneration. J Immunol 187: 4788-4799, 2011.

19. Prieto MA, Vázquez JA and Murado MA: Crocin bleaching antioxidant assay revisited: Application to microplate to analyse antioxidant and pro-oxidant activities. Food Chem 167: 299-310, 2015.

20. Du J, Chi Y, Song Z, Di Q, Mai Z, Shi J and Li M: Crocin reduces aspergillus fumigatus-induced airway inflammation and NF- $\kappa B$ signal activation. J Cell Biochem 119: 1746-1754, 2018.

21. Bolhassani A, Khavari A and Bathaie SZ: Saffron and natura carotenoids: Biochemical activities and anti-tumor effects Biochim Biophys Acta 1845: 20-30, 2014.

22. Xu GL, Li G, Ma HP, Zhong H, Liu F and Ao GZ: Preventive effect of crocin in inflamed animals and in LPS-challenged RAW 264.7 cells. J Agric Food Chem 57: 8325-8330, 2009.

23. Hosseinzadeh H and Jahanian Z: Effect of Crocus sativus L. (saffron) stigma and its constituents, crocin and safranal, on morphine withdrawal syndrome in mice. Phytother Res 24: 726-730, 2010

24. Hosseinzadeh H, Karimi G and Niapoor M: Antidepressant effects of Crocus sativus L. stigma extracts and its constituents, crocin and safranal, in mice. Acta Horticulturae 650: 435-445, 2004.

25. Mohamadpour AH, Ayati Z, Parizadeh MR, Rajbai O and Hosseinzadeh H: Safety evaluation of crocin (a constituent of saffron) tablets in healthy volunteers. Iran J Basic Med Sci 16 39-46, 2013.
26. Zhang JA, Yin Z, Ma LW, Yin ZQ, Hu YY, Xu Y, Wu D, Permatasari F, Luo D and Zhou BR: The protective effect of baicalin against UVB irradiation induced photoaging: An in vitro and in vivo study. PLoS One 9: e99703, 2014.

27. Park J, Seok JK, Suh HJ and Boo YC: Gardenia jasminoides extract attenuates the UVB-induced expressions of cytokines in keratinocytes and indirectly inhibits matrix metalloproteinase-1 expression in human dermal fibroblasts. Evid Based Complement Alternat Med 2014: 429246, 2014.

28. Zeng Q, Zhou F, Lei L, Chen J, Lu J, Zhou J, Cao K, Gao L, Xia F, Ding S, et al: Ganoderma lucidum polysaccharides protect fibroblasts against UVB-induced photoaging. Mol Med Rep 15: 111-116, 2017

29. El-Maraghy SA, Rizk SM and Shahin NN: Gastroprotective effect of crocin in ethanol-induced gastric injury in rats. Chem Biol Interact 229: 26-35, 2015.

30. Thushara RM, Hemshekhar M, Santhosh MS, Jnaneshwari S, Nayaka SC, Naveen S, Kemparaju K and Girish KS: Crocin, a dietary additive protects platelets from oxidative stress-induced apoptosis and inhibits platelet aggregation. Mol Cell Biochem 373: 73-83. 2013.

31. Bravo K, Duque L, Ferreres F, Moreno DA and Osorio E: Passiflora tarminiana fruits reduce UVB-induced photoaging in human skin fibroblasts. J Photochem Photobiol B 168: 78-88, 2017.

(i) (9) This work is licensed under a Creative Commons EY NG ND Attribution-NonCommercial-NoDerivatives 4.0 International (CC BY-NC-ND 4.0) License. 